\title{
The nerve deaf child-intrauterine rubella or not?
}

\author{
C S HOSKING, C PYMAN, AND B WILKINS \\ Department of Immunology, Royal Children's Hospital, Melbourne, Australia
}

SUMmARY We describe a laboratory test which is useful in determining whether deafness is due to intrauterine rubella. The study group consisted of 8 deaf patients with proved intrauterine rubella, 12 patients with familial deafness, and 17 controls. Blood was taken at time 0 from all of them. All the deaf children and 5 controls were immunised and further blood samples taken at 2 and 6 weeks. Each blood sample was analysed for the lymphocyte response to rubella in vitro and for the presence of rubella haemagglutination inhibition. All the rubella-affected patients had antibody titres to rubella at time 0 and there was no notable change after immunisation. None of these patients had a significant lymphocyte response to rubella antigen at any time. Eight of the familial deaf patients and 13 of the controls had positive antibody titres. With the exception of one patient whose results were equivocal, all the familial deaf patients and controls in whom antibodies were detected had lymphocyte responses to rubella. In those with undetectable antibodies the lymphocytes failed to respond in vitro to rubella antigen.

The diagnosis of intrauterine rubella is easy to confirm in an infant who has some of the classic features of the disease. ${ }^{1}$ In other rubella-affected children the clinical diagnosis may be difficult to make, particularly in those of mothers infected late in pregnancy whose only clinical feature may be nerve deafness which may not be diagnosed in infancy when viral culture could offer confirmation. ${ }^{2}$ This difficulty in diagnosis creates a problem in genetic counselling of a family with one nerve deaf child. If the aetiology of the deafness is intrauterine rubella infection, it is unlikely that subsequent children will be affected.

The purpose of this study was to test the hypothesis that the immunological response to rubella virus antigen will be different in patients whose deafness is due to intrauterine rubella than in patients with nerve deafness due to other causes. In so doing we hoped to develop a useful diagnostic test using readily available reagents.

\section{Materials and methods}

Patients and controls. Twenty patients with nerve deafness were investigated. In 8 of these there was irrefutable evidence of intrauterine rubella infection. Such evidence consisted of other major manifestations of rubella embryopathy - such as cataract and congenital heart lesions, or the isolation of rubella virus at birth, or an increase in rubella antibody titre in pregnancy after a viral infection suggestive of rubella. The mothers of 3 patients gave a history of a rash consistent with or proved to be rubella during pregnancy. These rashes occurred at 6,8 , and 12 weeks of pregnancy.

The 12 other nerve-deaf patients, consisting of five sets of siblings, all had a strong family history of nerve deafness. The ages of the intrauterine rubella patients ranged from 7 to 24 years with a median of 14. The ages of the other deaf patients ranged from 3 to 28 years with a median of 13. A further control group of 17 hospital staff had a median age of 24 years and ranged from 19 to 43 years.

All the deaf children and 5 staff members were immunised with rubella vaccine (Cendevax).

All subjects were bled at time 0 , and those who were immunised received immunisations 2 and 6 weeks later.

Lymphocyte culture. Mononuclear cells separated by Ficoll Isopaque density gradient centrifugation ${ }^{3}$ were cultured in the presence of a 1:10 dilution of rubella complement fixation antigen or rubella control antigen (Flow Laboratories) in Dulbeccos modification of MEM (DMEM, Flow Laboratories). The basic technique used was a modification of that of Buimovici-Klein et al. ${ }^{4}$ Quintuplicate cultures of $2 \times 10^{5}$ mononuclear cells were established in round bottomed Cooke microtitre trays in $0.2 \mathrm{ml}$ of DMEM, supplemented with $20 \%$ rubella antibody 
negative human plasma. Cultures were incubated for 8 days in $5 \% \mathrm{CO}_{2}$ at $37^{\circ} \mathrm{C}$ and during the last 24 hours were pulsed with tritiated thymidine, $1 \mu \mathrm{Ci}$ in $25 \mu \mathrm{l}$ (Amersham Cat No TRA61). Cells were harvested on glass fibre filters using a Skatron Titertek Cell Harvester and after drying and the addition of scintillant, the discs were counted in a beta counter for 1 minute. Results were determined as the mean of quintuplicate counts and expressed as the stimulation index (SI). SI=rubella antigen stimulated - (control Ag_background)/background.

In general there was no significant stimulation by the control antigen compared with background (no rubella antigen or control antigen present) counts which were in the range of 1000 to 5000 counts per minute.

Rubella antibody titres. Serum haemagglutination inhibition antibody titres were determined by standard laboratory techniques ${ }^{5}$ and expressed as the reciprocal of the dilution end point.

\section{Results}

Fig. 1 shows the antibody titre to rubella virus and the lymphocyte response in vitro to rubella antigen in the three groups at time 0 . It is evident that the results from the controls and from the patients whose deafness was not due to congenital rubella are very similar. The patients whose deafness was due to congenital rubella form a distinctly different pattern from the other two groups. Thus all the patients whose deafness was due to documented intrauterine rubella had an antibody titre to rubella and none

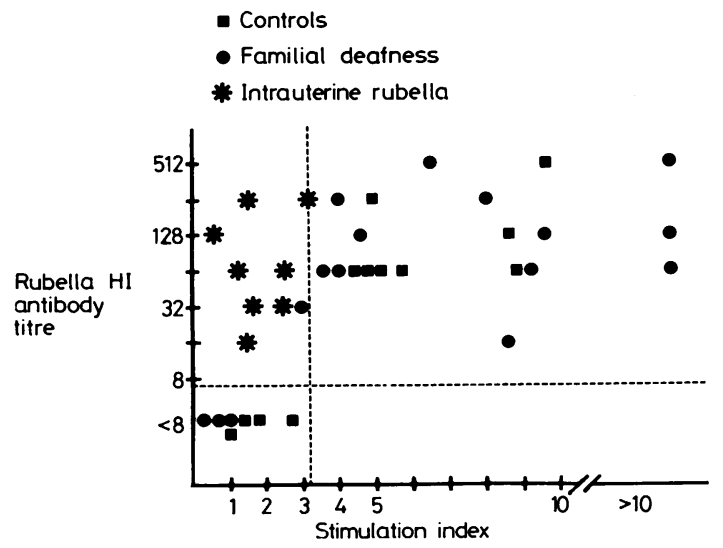

Fig. 1 Relationship between rubella haemagglutination inhibition antibody titre and lymphocyte stimulation by rubella antigen.

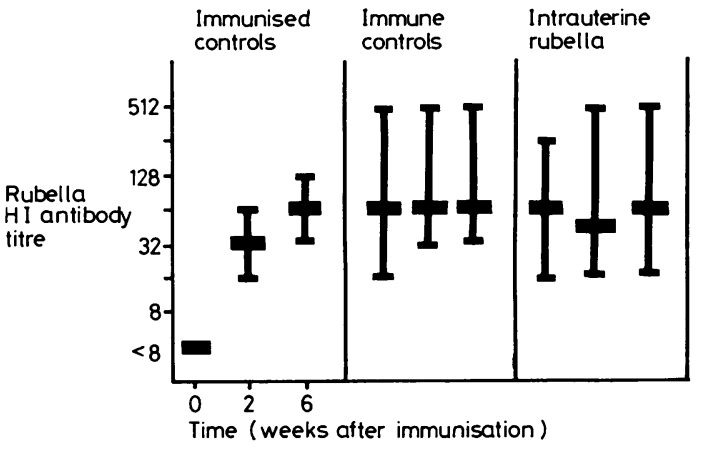

Fig. 2 Rubella haemagglutination inhibition antibody titre before $(0)$, and 2 and 6 weeks after immunisation with Cendevax vaccine. Both non-rubella deaf controls and laboratory controls have been grouped and divided into non-immune 'immunised' and those who had antibody 'immune' at the start of the study. The median is indicated by the heavy horizontal bar and the range by the lighter horizontal bars.

had positive lymphocyte responsiveness in vitro to rubella though one result was borderline (SI 3.2). However, with the exception of one patient (who had a response of 2.9), all the non-rubella deaf patients and controls who had antibody detectable, had a positive lymphocyte response in vitro, and all without antibody failed to respond in vitro.

Fig. 2 shows the antibody levels at 0,2 , and 6 weeks after immunisation. As can be seen, there was no significant difference (greater than two-tube difference from initial sample) in antibody titre of any patient or control whose time 0 specimen had antibody to rubella. By contrast, all the controls who did not have detectable antibody developed antibody after immunisation.

\section{Discussion}

The results suggest a satisfactory method of making a retrospective diagnosis of intrauterine rubella. Unfortunately, in this particular group of patients with proved intrauterine rubella, no patient had undetectable antibody. There is evidence that some patients with congenital rubella lose their antibody titre with time.$^{6}{ }^{7}$ However, such patients do not have an antibody response to rubella on subsequent immunisation. ${ }^{6}$ Thus while our own experience is of no help in this regard, there is good reason to believe that the patients whose deafness is due to intrauterine rubella and who at the time of testing have lost their antibody can be distinguished from other patients who have not been infected with rubella by their antibody response to immunisation. 
Our findings are in agreement with those of Buimovici-Klein et al. ${ }^{4}$ who demonstrated impaired lymphocyte responsiveness to rubella antigen in vitro in children with deafness due to intrauterine rubella. Some patients with intrauterine rubella have been reported as having evidence of cell mediated immunity to rubella in vitro. ${ }^{8}$ However the assay used was different from the one we used.

The lymphocyte response in vitro 2 and 6 weeks after immunisation did not always rise to significant levels in the antibody negative non-rubella deaf patients and controls. Two of 6 of this combined group had significant lymphocyte responses by 6 weeks.

One interesting feature is that in non-rubella patients and controls with antibody, rubella immunisation produced a decline in the lymphocyte responsiveness 2 weeks after immunisation.

Only one child with congenital rubella had a positive lymphocyte response to rubella antigen in any of the three samples.

With regard to the antibody-negative controls, it may be that the final 6-week sample was taken too early for maximal response as the 2 controls who had a low positive response $(3 \cdot 6,3 \cdot 9)$ by 6 weeks, had an increased response $(4 \cdot 5,4.5)$ by 4 months after immunisation. This suggestion would agree with the results of Heigl et al. ${ }^{9}$ who also used Cendevax. However Vesikari and Buimovici-Klein, ${ }^{10}$ using Almevax, found maximum lymphocyte response 3 weeks after immunisation of sero-negative controls.

We propose the following practical method for distinguishing the majority of nerve deaf children whose deafness is due to intrauterine rubella from those whose deafness is from other causes. Test a blood sample for antibody response to rubella virus and lymphocyte responsiveness in vitro to rubella antigen. If antibody and lymphocyte responsiveness are both present then the patient has had extrauterine infection with rubella virus. If antibody is present but lymphocyte response in vitro is negative then intrauterine rubella is the likely cause of the deafness. If antibody is absent and lymphocyte response is negative then rubella vaccination will distinguish the two groups. Patients whose deafness is due to intrauterine rubella will not have an antibody rise after immunisation ${ }^{6}$ whereas most non-immune subjects will sero-convert. ${ }^{611}$
Further study is needed to differentiate the few patients in whom lymphocyte response is marginal.

We thank the children, parents, and controls involved in the study; Mr E Kier for assistance in selecting patients from his files; Mr I Jack for the rubella antibody titres; $\operatorname{Dr} L \quad Z$ Cooper for encouragement.

This study was financially supported by a grant from the Deafness Foundation of Victoria.

\section{References}

1 Sever J L. Congenital rubella. Clin Perinatol 1979; 6 : 347-52.

2 Rossi M, Ferlito A, Polidoro F. Maternal rubella and hearing impairment in children. $J$ Laryngol Otol 1980; 94: 281-9.

3 Boyum A. Separation of leukocytes from blood and bone-marrow. Scand J Clin Lab Invest 1968; 21: Supplement 97.

4 Buimovici-Klein E, Lang P B, Ziring P R, Cooper L Z. Impaired cell-mediated immune response in patients with congenital rubella: correlation with gestational age at time of infection. Pediatrics 1979; 64: 620-6.

5 Lennette E H, Schmidt N J. Diagnostic procedures for viral, rickettsial, and chlamydial infections, fifth edition American Public Health Association: Washington DC; 1979; 727-66.

- Cooper L Z, Florman A L, Ziring P R, Krugman S. Loss of rubella hemagglutination inhibition antibody in congenital rubella. Am J Dis Child 1971; 122: 397-403.

? Hardy J B, Sever J L, Gilkeson M R. Declining antibody titers in children with congenital rubella. $J$ Pediatr 1969; 75: 213-20.

8 Fuccillo D A, Steele R W, Hensen S A, Vincent M M, Hardy J B, Bellanti J A. Impaired cellular immunity to rubella virus in congenital rubella. Infect Immun 1974; 9: $81-4$.

- Heigl Z, Wasserman J, Forsgren M. In vitro lymphocyte reactivity to rubella antigen following vaccination. Scand J Infect Dis 1980; 12: 13-20.

10 Vesikari T, Buimovici-Klein E. Lymphocyte responses to rubella antigen and phytohaemagglutinin after administration of the RA27/3 strain of live attenuated rubella vaccine. Infect Immun 1975; 11 : 748-53.

11 Peetermans J, du Pan R M, Huygelen C. Persistence of antibody titers after vaccination with rubella virus vaccine ('Cendehill' strain). Dev Biol Stand 1979; 43: 361-5.

Correspondence to Dr C S Hosking, Department of Immunology, Royal Children's Hospital, Flemington Road, Parkville, Victoria 3052, Australia.

Received 17 January 1983 